\title{
ANALISIS PREFERENSI MASYARAKAT TERHADAP KUALITAS PELAYANAN RUMAH SAKIT
}

\author{
Dini Amalia Putri ${ }^{\S}$, I Komang Gde Sukarsa ${ }^{2}$, Ketut Jayanegara ${ }^{3}$ \\ ${ }^{1}$ Program Studi Matematika, Fakultas MIPA - Universitas Udayana [Email: dini.amalia260@gmail.com] \\ ${ }^{2}$ Program Studi Matematika, Fakultas MIPA - Universitas Udayana [Email: sukarsakomang@yahoo.com] \\ ${ }^{3}$ Program Studi Matematika, Fakultas MIPA - Universitas Udayana [Email: ktjayanegara@unud.ac.id] \\ ${ }^{\S}$ Corresponding Author
}

\begin{abstract}
Conjoined analysis is a multivariate technique specifically developed to get people's preferences. The purpose of this study is to determine people's preferences for the quality of hospital services based on attributes to determine the combination of these attributes that are most desired by customers. This study uses primary data taken through surveys using a questionnaire. The survey conducted at Udayana Denpasar Hospital was applied with non-probability sampling techniques, namely accidental sampling with the number of samples needed was 100 respondents. The attributes used in this study were (a) physician services, (b) number of patients, (c) facilities, (d) location of the bathroom, and (e) price. The results showed that the most valued attribute by respondents was Facility. The combination of the level of each attribute that most influences the respondents in determining the room when doing hospitalization at the Level II Hospital of Udayana Denpasar is handled by a Specialist, consisting of 1 patient, bathroom, with facilities consisting of tv, air conditioning, refrigerator, cupboard, buffet, sofa, table, living room and bed for the patient's family, with a price of $>1,000,000$.
\end{abstract}

Keywords : Attribute, Conjoint Analysis, Level, Non-Probability Sampling.

\section{PENDAHULUAN}

Di era pasar kompetitif, banyak ditemui rumah sakit yang dibangun oleh pemerintah maupun swasta. Rumah sakit sebagai penyelenggara pelayanan kesehatan dituntut untuk siap bersaing baik dalam kualitas pelayanan, pola pemasaran, dan kelengkapan sarana maupun prasarana yang sesuai dengan kebutuhan dan tuntutan masyarakat agar dapat terus berkembang.

Salah satu penyedia jasa pelayanan kesehatan yang berada di Denpasar adalah Rumah sakit Tingkat II Udayana. Rumah sakit tingkat II Udayana Denpasar mempunyai tugas untuk memberikan dukungan dan pelayanan kesehatan kepada warga TNI-AD, PNS, dan keluarganya, juga dalam memberikan pelayanan kesehatan integrasi kepada pasien rujukan dari personel TNI-AU, TNI AL serta memberikan pelayanan kesehatan kepada masyarakat umum, pasien BPJS Dinas dan BPJS Umum.

Hasil penelitian Putri (2016) tentang pengaruh kualitas pelayanan kesehatan terhadap kepuasan pasien peserta BPJS di Rumah Sakit
Tingkat II Udayana Denpasar dengan menggunakan analisis regresi linier berganda masih terdapat pasien yang merasa belum puas terhadap pelayanan dan fasilitas yang disediakan oleh pihak Rumah Sakit Tingkat II Udayana Denpasar. Usaha yang dilakukan untuk meningkatkan kualitas pelayanan, maka pihak rumah sakit perlu meningkatkan pelayanan kesehatan, dan harus mengetahui atribut-atribut sesuai dengan standar pelayanan yang diinginkan masyarakat.

Pemilihan kamar merupakan hal utama yang haru dimengerti oleh pasien pada saat melakukan rawat inap, dan pasien harus mengerti kondisi kamar serta kelengkapan fasilitas yang akan ditawarkan oleh pihak rumah sakit. Kondisi kamar juga sangat berpengaruh terhadap kenyamanan yang dirasakan oleh pasien sehingga diharapkan dapat membantu proses penyembuhan sehingga pasien dapat merasa nyaman dengan kamar yang mereka pilih. Menurut Aniroen (1991) setidaknya ada 5 fungsi rawat inap yaitu (1) Pelayanan Tenaga 
Medis, (2) Pelayanan Tenaga Para Medis, (3) Ruang Perawatan, (4) Pelayanan Penunjang Medis, dan (5) Pelayanan Administrasi dan Keuangan. Dari uraian tersebut terlihat betapa pentingnya fungsi rawat inap sebagai pelayanan kepada masyarakat dan bagi pihak rumah sakit sendiri.

Analisis Konjoin menurut Hair et al. (2010) adalah teknik multivariat yang dikembangkan secara khusus untuk memahami bagaimana preferensi pelanggan terhadap suatu jenis objek (produk, jasa, atau ide-ide). Analisis konjoin akan membentuk kombinasi dari atribut-atribut yang ada, sehingga masyarakat dapat memberikan perkiraan preferensi dengan menilai objek yang dibentuk oleh kombinasi dari atribut tersebut. Nilai kegunaan dapat dicari untuk mengetahui preferensi subjektif oleh individu yang mewakili nilai keseluruhan dari suatu objek tertentu dan mengetahui tingkat kepentingan atribut sebagai gambaran mengenai peran suatu atribut yang memengaruhi responden dalam memilih suatu produk.

Tujuan dilakukannya penelitian ini adalah untuk menentukan preferensi masyarakat terhadap kualitas pelayanan rumah sakit berdasarkan atribut-atribut yang berpengaruh terhadap penilaian masyarakat dan menentukan kombinasi antar atribut yang paling diinginkan masyarakat Adapun secara umum model dasar analisis konjoin (Kuhfeld, 2000) adalah:

$$
Y_{i j}=\alpha_{0}+\sum_{i=1}^{m} \sum_{j=1}^{k} \alpha_{i j} x_{i j}+\varepsilon_{i j}
$$

Keterangan:

$Y_{i j}=$ Peringkat seluruh responden

$\alpha_{0}=$ Intersep

$k=$ Banyak taraf dari atribut ke- $i$

$m=$ Jumlah atribut

$x_{i j}=$ Peubah boneka atau variabel dummy dari atribut ke- $i$ taraf ke- $j$

$\alpha_{i j}=$ Nilai kegunaan atribut ke- $i$ taraf ke- $j$

$\varepsilon_{i j}=$ Galat

Hasil penelitian Apriyani (2017) dengan menggunakan analisis faktor konfirmatori dan SEM PLS untuk mengetahui faktor-faktor yang memengaruhi tingkat kepuasan keluarga pasien terhadap kualitas layanan keperawatan rawat inap, untuk mengetahui hubungan persepsi keluarga pasien rawat inap terhadap kualitas layanan yang diberikan dan untuk mengetahui hubungan kualitas layanan rawat inap terhadap tingkat kepuasan yang diterima di RSUD Wangaya. Hasil penelitian yang diperoleh sesuai dengan teori memang benar lima faktor yang memengaruhi kualitas layanan yaitu perhatian (empathy), sarana fisik (tangible), jaminan (assurance), kehandalan (reliability), dan daya tanggap (responsiveness). Dari kelima faktor tersebut tiga faktor diantaranya yaitu perhatian, jaminan, dan kehandalan menjadi fokus perhatian bagi keluarga pasien rawat inap untuk meningkatkan kualitas layanan sedangkan faktor sarana fisik dan daya tanggap perlu tetap ditingkatkan sehingga menjadikan kualitas layanan menjadi lebih baik. Kualitas layanan rawat inap mampu menjelaskan keragaman sebesar $84 \%$ terhadap tingkat kepuasan keluarga pasien maupun pasien.

Wahyuni (2015) menggunakan pendekatan analisis konjoin untuk mengetahui preferensi peserta BPJS terhadap kualitas pelayanan di rumah sakit Dr. Pirngadi dan rumah sakit Martha Friska Medan. Hasil penelitian yang diperoleh yaitu preferensi peserta BPJS terhadap kualitas pelayanan berdasarkan urutan subatribut terpenting yang sama antara Rumah Sakit Dr. Pirngadi dan Rumah Sakit Martha Friska terdapat pada atribut responsiveness, assurance, dan emphaty, sedangkan yang berbeda terdapat pada atribut reliability dan tangible. Kombinasi level dari subatribut yang sama antara kedua rumah sakit tersebut terdapat pada atribut emphaty, sedangkan yang berbeda terdapat pada atribut reliability, responsiveness, assurance, tangible.

\section{METODE PENELITIAN}

\section{A. Jenis dan Sumber Data}

Sumber data yang digunakan dalam penelitian ini ialah data primer. Data primer dalam penelitian ini diperoleh dengan cara menyebarkan angket kepada masyarakat untuk mengetahui preferensi responden terhadap kualitas pelayanan Rumah Sakit Tingkat II Udayana Denpasar.

Metode pengambilan sampel yang digunakan adalah Purposive Sampling Method (pengambilan sampel secara tidak acak) yaitu pengambilan elemen-elemen yang dijadikan sampel dengan maksud dan tujuan tertentu. Sampel populasi dalam penelitian ini adalah seluruh masyarakat yang pernah melakukan rawat inap dan mendapatkan pelayanan di Rumah Sakit Tingkat II Udayana Denpasar.

Metode yang digunakan untuk mengumpulkan data primer yaitu melalui penyebaran angket secara langsung kepada pasien maupun keluarga pasien. Mengingat adanya pertimbangan keterbatasan waktu dan 
biaya penelitian maka ditentukan bahwa sampel dalam penelitian ini sebanyak 100 responden dianggap memadai.

\section{B. Teknik Analisis Data}

Tahapan analisis dalam penelitian ini yang dilakukan adalah:

1). Menghitung utility function, digunakan untuk mengetahui preferensi subjektif oleh individu yang mewakili nilai keseluruhan dari suatu objek tertentu (Härdle \& Simar, 2003) Langkah-langkah yang dilakukan untuk mencari nilai kegunaan ialah

(a) Menentukan stimuli,

Stimuli adalah kombinasi antara atribut dengan taraf. Dari 5 atribut dimana atribut pertama terdiri dari 2 taraf, atribut kedua terdiri dari 3 taraf, atribut ketiga terdiri dari 4 taraf, atribut keempat terdiri dari 2 taraf dan atribut kelima terdiri dari 3 taraf, didapat jumlah kombinasi yang mungkin untuk disusun sebanyak 144 stimuli yang diperoleh dari hasil perkalian tiap taraf atribut $2^{1} \times 3^{1} \times 4^{1} \times 2^{1} \times 3^{1}=2 \times 3 \times 4 \times 2 \times 3$.

Dengan jumlah stimuli sebanyak itu, akan menyulitkan responden mengevaluasi kombinasi stimuli tersebut. Membutuhkan waktu yang lama bagi para responden untuk mengevaluasinya. Sehingga untuk memudahkan responden, diambil 6 stimuli sesuai dengan pelayanan yang ditawarkan oleh pihak rumah sakit sehingga diharapkan dapat memudahkan pasien dalam menentukan pilihan dalam mengevaluasi angket.

(b) Menghitung nilai rata-rata ranking keseluruhan (K)

$$
K=\frac{\sum_{i=1}^{n} k_{i}}{n}
$$

Keterangan:

$k_{i}=$ nilai rangking ke- $i$

$n=$ jumlah rangking

(c) Menghitung nilai rata-rata ranking tiap taraf atribut.

$$
\overline{R_{\imath j}}=\frac{\sum r_{X_{i j}}}{n_{r}}
$$

Keterangan:

$\overline{R_{\imath \jmath}}=$ Rata-rata ranking atribut ke-i taraf ke-j

$\sum r_{X_{i j}}=$ Jumlah ranking yang termasuk ke dalam atribut ke-i taraf ke-j

$i=$ banyaknya atribut

$j \quad=$ banyaknya taraf atribut

$n_{r} \quad=$ jumlah banyak taraf atribut dalam

$$
X_{i j}
$$

(d) Menghitung nilai deviasi.

Keterangan:

$$
d_{X_{i j}}=\overline{R_{l j}}-K
$$

$d_{X_{i j}}=$ Nilai deviasi atribut ke-i taraf ke-j

(e) Menghitung Nilai Kegunaan (utilitas).

$U_{X_{i j}}=$ Nilai kegunaan dari atribut ke- $i$ taraf
ke-j

2). Menghitung nilai kepentingan relative, digunakan mengetahui tingkat kepentingan atribut sebagai gambaran mengenai peran suatu atribut yang memengaruhi responden dalam memilih suatu produk. Menurut (Hair et al, 2010) Langkah-langkah yang dilakukan untuk mencari nilai kepentingan ialah

(a) Menghitung Jumlah deviasi kuadrat.

Keterangan:

$$
J D K=\sum_{i=1}^{m} \sum_{j=1}^{k}\left(d_{X_{i j}}\right)^{2}
$$

$J D K=$ Jumlah deviasi kuadrat $d_{X_{i j}}=$ Nilai deviasi atribut ke-i taraf ke-j

(b) Menghitung Nilai Baku.

$$
N B=\frac{n}{J D K}
$$

Keterangan:

$N B=$ Nilai Baku

$n=$ jumlah taraf atribut

(c) Menghitung Koefisien taraf atribut.

$$
c_{X_{i j}}=\sqrt{\left(d_{X_{i j}}\right)^{2} \times N B}
$$

Keterangan:

$c_{X_{i j}}=$ Koefisien taraf atribut

(d) Menghitung Range setiap Atribut.

$$
C_{X_{i}}=\max _{X_{i}}-\min c_{X_{i}}
$$

Keterangan:

$C_{X_{i}}=$ Range setiap atribut

(e) Menghitung Total Range Atribut

$$
I_{i}=\sum_{i=1}^{m} C_{X_{i}}
$$

Keterangan:

$I_{i}=$ Total range atribut

(f) Menghitung Tingkat Kepentingan Atribut.

Keterangan:

$$
W_{i}=\frac{C_{X_{i}}}{I_{i}} \times 100 \%
$$

$W_{i}=$ Tingkat kepentingan atribut

3). Interpretasi Hasil, untuk memperoleh informasi tentang tingkat kepentingan atribut dan nilai kegunaannya. 


\section{HASIL DAN PEMBAHASAN}

\section{A. Analisis Nilai Kegunaan}

Nilai Kegunaan menunjukkan preferensi subjektif oleh individu yang mewakili nilai keseluruhan dari suatu objek. Berdasarkan hasil analisis konjoin dengan bantuan software SPSS 22.0 (Statistical Package for Social Sciences), diperoleh nilai kegunaan seperti dalam bentuk Tabel 1 yang menggambarkan preferensi dari responden di Rumah Sakit Tingkat II Udayana Denpasar.

Tabel 1. Nilai Utility Function

\begin{tabular}{|c|c|c|}
\hline & $\begin{array}{c}\text { Utility } \\
\text { Estimate }\end{array}$ \\
\hline \multirow{2}{*}{$\begin{array}{c}\text { Letak } \\
\text { KM }\end{array}$} & Kamar mandi dalam & .150 \\
\hline & Kamar mandi luar & -.150 \\
\hline \multirow[t]{2}{*}{ PD } & $\begin{array}{c}\text { Ditangani Asisten Dokter } \\
\text { Spesialis }\end{array}$ & .110 \\
\hline & Ditangani Dokter Spesialis & .220 \\
\hline \multirow{3}{*}{ JP } & Terdiri dari 1 pasien & -.580 \\
\hline & Terdiri dari 1-2 pasien & -1.160 \\
\hline & Terdiri dari 2 pasien & -1.740 \\
\hline \multirow{4}{*}{$\begin{array}{c}\text { Fasilita } \\
\text { s }\end{array}$} & Premium VIP & -.120 \\
\hline & Super VIP & -.240 \\
\hline & Standar & -.360 \\
\hline & Biasa & -.480 \\
\hline \multirow{3}{*}{ Harga } & $>$ Rp 1.000.000 & -.130 \\
\hline & $500.000-1.000 .000$ & -.260 \\
\hline & $<\operatorname{Rp} 500.000$ & -.390 \\
\hline \multicolumn{2}{|r|}{ (Constant) } & 5.125 \\
\hline
\end{tabular}

Level yang paling disukai ditunjukkan dengan nilai level yang paling besar untuk setiap taraf atribut. Kombinasi level-level dari setiap atribut yang paling memengaruhi responden dalam menentukan kamar saat melakukan rawat inap di Rumah Sakit Tingkat II Udayana Denpasar adalah ditangani oleh Dokter Spesialis, terdiri dari 1 pasien, kamar mandi dalam, dengan fasilitas yang terdiri dari tv, ac, kulkas, lemari, buffet, sofa, meja, ruang tamu, dan tempat tidur untuk keluarga pasien, dengan harga $>1.000 .000$.

\section{B. Analisis Nilai Kepentingan Relatif}

Nilai kepentingan menunjukkan atribut mana yang paling penting dalam memengaruhi preferensi responden. Berdasarkan hasil analisis konjoin dengan bantuan software SPSS 22.0 (Statistical Package for Social Sciences), diperoleh nilai kepentingan relatif pada Tabel 2 dapat digambarkan secara visual menggunakan diagram batang pada Gambar 1.

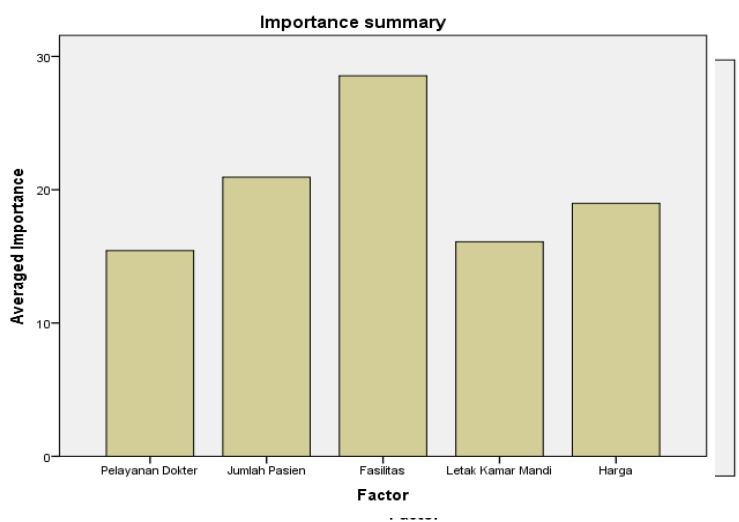

Gambar 1. Diagram Batang Nilai Kepentingan Relatif

Tabel 2. Nilai Kepentingan Relatif

\begin{tabular}{|c|c|}
\hline \multicolumn{2}{|c|}{ Nilai Kepentingan Relatif } \\
\hline Pelayanan Dokter & 15.437 \\
\hline Letak Kamar Mandi & 16.098 \\
\hline Jumlah Pasien & 20.937 \\
\hline Fasilitas & 28.549 \\
\hline Harga & 18.980 \\
\hline
\end{tabular}

Tabel 2 menunjukkan bahwa atribut yang paling penting dalam memengaruhi preferensi masyarakat dalam memilih kamar saat akan melakukan rawat inap adalah atribut Fasilitas yang terdapat dengan Nilai Kepentingan Relatif yaitu 28.549. Disusul dengan atribut selanjutnya yang memengaruhi preferensi masyarakat dalam memilih kamar jika akan melakukan rawat inap adalah atribut Jumlah pasien dengan nilai kepentingan relatif yaitu 20.937, harga dengan nilai kepentingan relatif yaitu 18.980, letak kamar mandi dengan nilai kepentingan relatif yaitu 16.098, dan pelayanan dokter dengan nilai kepentingan relatif yaitu 15.437. Secara umum dapat disimpulkan bahwa atribut yang pertama kali dipertimbangkan oleh masyarakat dalam memilih kamar jika akan melakukan rawat inap adalah fasilitas.

\section{KESIMPULAN DAN SARAN}

\section{A. Kesimpulan}

Berdasarkan hasil analisis, dapat ditarik beberapa kesimpulan sebagai berikut:

1. Atribut yang paling memengaruhi responden dalam menentukan kamar saat melakukan rawat inap di Rumah Sakit Tingkat II Udayana Denpasar berdasarkan urutan nilai kepentingannya adalah fasilitas, jumlah 
pasien, harga, letak kamar mandi, dan pelayanan dokter

2. Kombinasi level-level dari setiap atribut yang paling memengaruhi responden dalam menentukan kamar saat melakukan rawat inap di Rumah Sakit Tingkat II Udayana Denpasar adalah ditangani oleh Dokter Spesialis, terdiri dari 1 pasien, kamar mandi dalam, dengan fasilitas yang terdiri dari tv, ac, kulkas, lemari, buffet, sofa, meja, ruang tamu, dan tempat tidur untuk keluarga pasien, dengan harga $>1.000 .000$.

\section{B. Saran}

Fasilitas merupakan atribut yang paling penting menurut responden sehingga diharapkan pihak rumah sakit dapat memperhatikan dan meningkatkan pelayanan fasilitas yang terdapat di rumah sakit agar sesuai dengan standar pelayanan yang diinginkan responden. Fasilitas dengan level TV, AC, Kulkas, Lemari, Buffet, Sofa, Meja, Ruang Tamu,dan Tempat tidur untuk keluarga pasien dimana fasilitas tersebut hanya didapatkan di Premium VIP melihat jumlah kamar tersebut hanya terdiri dari 1 kamar, sehingga disarankan kepada pihak rumah sakit dapat menambah jumlah kamar Premium VIP sesuai dengan preferensi responden.

\section{DAFTAR PUSTAKA}

Atimura. (2017). Analisis Konjoin Untuk Menemukan Kombinasi Karakter Kartu Perdana Seluler GSM Yang Dipilih Oleh Mahasiswa Universitas Halu Oleo Kendari. Skripsi. Fakultas Matematika dan Ilmu Pengetahuan Alam, Universitas Halu Oleo.

Aniroen, S. (1991). Kebijakan Departemen Kesehatan Dalam Upaya Peningkatan Mutu Pelayanan Rumah Sakit. Jakarta: Cerita Dunia Kedokteran.

Apriyani, L. (2017). Model Persamaan Struktural pada Hubungan Tingkat Kepuasan Pasien Terhadap Kualitas Layanan Rawat Inap (Studi Kasus: RSUD Wangaya Kota Denpasar). E-Jurnal Matematika, Vol. 6, No 3.

Frank, R. (2011). Microeconomics and Behavior. New York: McGraw-Hill.

Hair, J.F., Black, W.C, Babin, B.J., \& Anderson, R.E. (2010). Multivariate Data Analysis. New Jersey: Prentice-Hall Internasional.
Hardle, W., \& Simar, L. (2003). Applied Multivariate Statistical Analysis. Berlin: Springer.

Kuhfeld, W. 2000. Conjoint Analisis Examples. SAS Institute, Inc. Tersedia di http://www.sawtoothsoftware.com, diakses 1 Maret 2019.

Putri, A. D. (2016). Pengaruh Kualitas Pelayanan Kesehatan Terhadap Kepuasan Pasien Peserta BPJS di Rumah Sakit Tingkat II Udayana Denpasar. Citizen Charter, Vol. 1, No. 1.

Wahyuni, T. (2015). Perbandingan Preferensi Peserta BPJS Terhadap Kualitas Pelayanan Di Rumah Sakit Dr. Pirngadi Dan Rumah Sakit Martha Friska Medan Tahun 2015. Kebijakan, Promosi Kesehatan dan Biostatiskik, Vol. 1, No. 2. 